
and Allied Seiences (IJBPAS) 'A Bridge Betusen Caboratory and QRendo'

www.ibpas.com

\title{
PHYTOCHEMICAL INVESTIGATION, ANTIOXIDANT AND CYTOTOXIC POTENTIAL OF Dracaena reflexa Lam.
}

\author{
PRAVALIKA KUCHANA, SUJATHA E* \\ Department of Botany, Osmania University, Telangana, India, 500007 \\ *Corresponding Author: Sujatha E: E Mail: sujatha@osmania.ac.in
}

Received 25 ${ }^{\text {th }}$ June 2021; Revised 28 ${ }^{\text {th }}$ July 2021; Accepted 29 ${ }^{\text {th }}$ Aug. 2021; Available online $25^{\text {th }}$ Sept. 2021

https://doi.org/10.31032/IJBPAS/2021/10.9.1054

\begin{abstract}
Cancer is one of the leading causes of mortality with a huge socio-economic burden. A blend of intrinsic and extrinsic factors is involved in the pathology and progression of various cancers. Stress is an initiator of chronic illness and can trigger pro-oncogenes to oncogenes. Polyphenols such as flavonoids and tannins are the known antioxidants to thrash out free radical associated stress. Natural medicine such as nutraceuticals is refurbishing to reach the basic health requirements and for the management of lifestyle disorders. The present investigation is aimed to evaluate the total phenolic, flavonoid and tannin content, antioxidant activity of Dracaena reflexa Lam. leaves.

Total phenolic content was estimated by Folin-Ciocalteu colorimetric method taking gallic acid as standard. Whereas, total flavonoid content was determined by $\mathrm{AlCl}_{3}$ colorimetric assay using Quercetin as standard. The absorbance was measured at $765 \mathrm{~nm}, 415 \mathrm{~nm}$ and $500 \mathrm{~nm}$ respectively. Antioxidant activity was measured by DPPH and NO free radical scavenging assay using standard protocols, taking ascorbic acid as a reference. The cytotoxicity was assessed through MTT assay using cancer cell lines such as Cervical cancer-Hela, Ovarian cancer- SKOV3, Breast cancerMDAMB231, Pancreatic cancer-Panc-1, Prostate cancer-PC3, Murine melanoma-B16F10 and embryonic lung epithelial cell- L 132 by comparing with Doxorubicin.

From the results, the phytochemical analysis revealed that $D$. reflexa is having total phenols $(54 \pm 0.67 \mathrm{mgGAE} / \mathrm{gm})$, total flavonoids $(54 \pm 0.67 \mathrm{mgQE} / \mathrm{gm})$ and total tannins $(187.3 \pm 1.24 \mathrm{mgTAE} / \mathrm{gm})$ with potent antioxidant activity (DPPH assay $\mathrm{IC}_{50}=45.5$; NO free radical scavenging assay $\left.\mathrm{IC}_{50}=27.99\right)$. The extract was found to inhibit the proliferation of prostate cancer (PC-3) cells $(9.84 \pm 1.12 \mu \mathrm{M})$ effectively followed by Ovarian cancer (SKOV3; $14.02 \pm 2.23 \mu \mathrm{M}$ ), Breast cancer (MDAMB231; 14.85 $\pm 1.16 \mu \mathrm{M})$ and Pancreatic cancer (Panc-1; 17.08 $\pm 1.34 \mu \mathrm{M})$.
\end{abstract}


The phytochemicals present in the extracts such as alkaloids, carbohydrates, phenols, saponins, especially tannins and flavonoids, either alone or synergistically may contribute to the reported antioxidant and cytotoxic activities.

Keywords: Dracaena reflexa Lam, antioxidant, total phenolic content, total flavonoid content, total tannin content, DPPH assay, NO free radical scavenging assay, MTT assay

\section{INTRODUCTION}

The cell is producing free radicals as a part of defence mechanism to encounter the parasitic entry into the cytoplasm. The excess production led to cellular stress and can be revamped by the scavenging enzymes such as superoxide dismutase and catalase. When the equilibrium between the generation and neutralization of the free radicals is disturbed, the cell will be under stress and triggers chronic or progressive neurodegenerative, cardiovascular disorders and aging. To support the scavenging mechanism and restoration of cellular health, an external supply of antioxidants is necessary and natural antioxidants such as flavonoids, tocopherol and tannins are well-known for their potent adaptogenic properties and health benefits with minimum risks over the synthetic antioxidants. $^{1,2}$

Cancer is a dangerous disease characterized by the uncontrolled proliferation of cells that develops as tumors which can spread to another organ of the body through metastasis and can settle and grow as new tumors by angiogenesis that aggravate the survival of the healthy cells due to hypoxia and malnutrition. ${ }^{3}$ The pathophysiology of cancer is very complex that involves various means and one is independent of another. Chemical, environmental, genetic and unknown reasons for the development of tumors were stockpiled in the literature. ${ }^{4}$ Researchers are struggling to develop new anticancer agents with minimal side effects. As of now, the majority of the deaths are due to various cancers worldwide. Breast, lung, colon and rectal cancers are the top among the other types. More than 10 million patients died of various cancers in $2020 .^{5}$ Cancer ranked first or second to cause death to people, especially for elderly people. Deaths before 70 years are mostly due to cancer both in males and females. Comparatively, males are at higher risk than females. Breast and lung cancers shared majority of the cases and lung cancer is having more mortality than other cancers followed by colon and rectum cancers. Socio-economic burden is increasing both in developed and developing countries gradually. ${ }^{6}$

Herbs are the primary source of medicine, comparatively safer than synthetic drugs especially in long-term therapy and culturally accepted. The diversified 
phytochemicals present in the plants either alone or synergistically act to restore bodily health. ${ }^{7}$ The current approach towards drug discovery is shifting towards natural medicine and various exploration techniques have been developed to study the phytochemical and pharmacological aspects of plants. ${ }^{8}$

Dracaena reflexa Lam. of Asparagaceae family famous as the song of India is a small shrub that grows as an ornamental plant with simple, lanceolate and spiral leaves. Traditionally it is used to treat fevers including malaria, painful menstruation, bacterial \& amoebic dysentery and as a topical haemostat. ${ }^{9}$ Pharmacological and phytochemical evidence is necessary to understand the traditional applications of $D$. reflexa. In this regard, the current research focussed to explore the total phenolic, total flavonoid, total tannin content, antioxidant activity and estimating the cytotoxic potential of various extracts of $D$. reflexa leaves using MTT assay. The extracts were also subjected to preliminary phytochemical screening to determine the presence of secondary metabolites.

\section{MATERIALS AND METHODS}

Plant material

Dracaena reflexa Lam. leaves were collected from Osmania University campus, Telangana and authenticated by
Dr. K. Madhava Chetty, Assistant Professor, Department of Botany, Sri Venkateswara University, Tirupati and voucher specimen (Pt 0733) was preserved in the herbarium.

\section{Reagents and chemicals}

All the chemicals and reagents were procured from Sigma Aldrich (laboratory grade).

\section{Preparation of extracts}

The leaves of D. reflexa were collected and dried under shade. The dried leaves were powdered and subjected to defatting with petroleum ether prior to the exhaustive Soxhlet extraction with methanol. The extracts were collected by filtration, evaporation of solvent subsequently to get in solid form and percentage yield was calculated. $^{10}$

\section{Phytochemical screening}

The preliminary phytochemical investigation of methanolic leaf extract of D. reflexa was carried out by adopting standard protocols. ${ }^{11}$

\section{Estimation of total phenolic content}

Total phenolic content was estimated for $D$. reflexa as described by Singleton et al., (1965) with minor modifications. A stock solution was prepared for gallic acid and diluted to various concentrations with methanol ranging from $25-100 \mu \mathrm{g} / \mathrm{mL}$. $10 \mathrm{~mL}$ of Folin-Ciocalteu (10\%) reagent was incubated with $\mathrm{Na}_{2} \mathrm{CO}_{3}(7.5 \%$ w/v; 
makeup to $10 \mathrm{~mL}$ ) for two hours at room temperature. The absorbance was measured with UV-visible spectrophotometer $(765 \mathrm{~nm})$ in triplicates, a calibration curve was plotted and total phenolic content was expressed as mg of gallic acid equivalents (GAE) per gram of sample in dry weight $(\mathrm{mg} / \mathrm{g}){ }^{12}$

\section{Estimation of total flavonoid content}

Dowd method was employed to estimate the total flavonoid content of D. reflexa. 1 $\mathrm{mL}$ of the sample solution (extracts and Quercetin) was incubated for 0.5 hours with $0.2 \mathrm{~mL}$ of $10 \%(\mathrm{w} / \mathrm{v})$ Aluminum chloride solution, $0.2 \mathrm{~mL}(1 \mathrm{M})$ potassium acetate and the required quantity of distilled water to make $6 \mathrm{~mL}$. The absorbance was measured with UV-visible spectrophotometer $(415 \mathrm{~nm})$ in triplicates. The outcome data were expressed as $\mathrm{mg} / \mathrm{g}$ of quercetin equivalents in milligrams per gram (mg QE/g) of dry extract. ${ }^{13}$

\section{Estimation of total tannin content}

Broadhurst method was adapted to estimate total condensed tannin content with little modification. Sample solution $(0.4 \mathrm{~mL})$ is incubated with vanillin (4\% in methanol; 3 $\mathrm{mL}$ ) solution and $1.5 \mathrm{~mL}$ of concentrated hydrochloric acid for $15 \mathrm{~min}$ with sequential recordings of the absorbance values at $500 \mathrm{~nm}$. The condensed tannin content was expressed as mg of tannic acid equivalents per $\mathrm{mg}$ dry matter (mg
TAE/gm) dry weight. All the experiments were run in triplicate. The mean values and standard deviations were calculated. ${ }^{14}$

\section{In vitro antioxidant assay}

DPPH radical scavenging assay:

The free radical scavenging activity of $D$. reflexa leaf methanolic extracts was estimated by taking $0.2 \mathrm{~mL}$ of the extract solution mixed with $2 \mathrm{~mL}$ of DPPH solution $(0.5 \mathrm{mM})$ followed by 20 minutes incubation at room temperature. Ascorbic acid was served as a reference standard and the absorbance was measured at $515 \mathrm{~nm}$ for individual extracts in triplicates. The antioxidant activity was calculated using the formula given below. ${ }^{15}$

$\%$ Free radical scavenging activity $=\left[\left(\mathrm{A}_{0^{-}}\right.\right.$

$$
\left.\left.\mathrm{A}_{\mathrm{s}}\right) / \mathrm{A}_{0}\right] \times 100
$$

Where,

$\mathrm{A}_{0}$ is the absorbance of blank (DPPH solution alone)

$\mathrm{A}_{\mathrm{s}} \mathrm{s}$ the absorbance of the test (DPPH + sample)

Nitric oxide radical scavenging assay:

Leaf methanolic extracts of $D$. reflexa were screened for nitric oxide radical scavenging activity by mixing $0.5 \mathrm{~mL}$ of the test solution with $2 \mathrm{~mL}$ of sodium nitroprusside $(10 \mathrm{mM})$ and $0.5 \mathrm{~mL}$ of phosphate buffer (pH-7.4) will be mixed with $0.5 \mathrm{~mL}$ of the test solution and incubated for $150 \mathrm{~min}$ at $25^{\circ} \mathrm{C}$. Ascorbic acid solution and DMSO served as standard and control respectively. 
Equal volumes $(0.5 \mathrm{~mL}$ each $)$ of Griess reagent and test samples were incubated together for $30 \mathrm{~min}$ at $25{ }^{\circ} \mathrm{C} .{ }^{16}$ The absorbance was recorded at $540 \mathrm{~nm}$ and the percentage of nitric oxide inhibition was calculated as:

Percentage of nitric oxide radical

scavenging assay $=\left[\left(\mathrm{A}_{0}-\mathrm{A}_{\mathrm{s}}\right) / \mathrm{A}_{0}\right] \times 100$

Where,

$\mathrm{A}_{0}$ was the absorbance of control

$A_{s}$ was the absorbance of the treated sample

3-(4,5-dimethylthiazol-2-yl)-2,5-diphenyl tetrazolium bromide (MTT) assay

The cytotoxic potential of leaf methanolic extracts of $D$. reflexa was determined by MTT assay using Cervical cancer-Hela, Ovarian cancer- SKOV3, Breast cancerMDAMB231, Pancreatic cancer-Panc-1, Prostate cancer-PC3, Murine melanomaB16F10 and embryonic lung epithelial cellL 132, which were obtained from American Type Culture Collection (ATCC), 10801 University Boulevard Manassas, VA 20110, USA. The purple formazan produced by the reduction of MTT salt with mitochondrial enzymes represents the viability of cells and the intensity measured spectrophotometrically can be proportionate to the quantity of the living cells and can be expressed as $\mathrm{IC}_{50}$ values. The cells are incubated in a 96 well plate with the test samples at standard conditions $\left(37^{\circ} \mathrm{C}, 5 \% \mathrm{CO}_{2}, 72\right.$ hours) with subsequent
MTT $(20 \mu l, 2 \mathrm{mg} / \mathrm{ml}$, phosphate-buffered saline) treatment followed by 3 hours incubation under same conditions. The colored formazan was extracted with DMSO $(100 \mu l)$ and the intensity was measured using a spectrophotometer (540 $\mathrm{nm}$ ) in triplicates and the values are compared with standard (Doxorubicin) and blank. $^{17}$

\section{RESULTS}

\section{Preliminary phytochemical screening}

The preliminary phytochemical study of methanolic extract of $D$. reflexa exposed that the extracts are instituted with various secondary metabolites such as Alkaloids, saponins, flavonoids, tannins, amino acids and carbohydrates (Table 1).

\section{Total phenolic content}

Phenols can be directly interrelated to their protecting effect against the cellular stress in the body. The total phenolic content of methanolic extract of $D$. reflexa leaves was evaluated by Folin-Ciocalteu method taking gallic acid as the standard. A calibration curve was plotted with the absorbance values against different concentrations of gallic acid. Total phenolic content of the extracts was calculated from the regression equation of the calibration curve $\left(6.819 x+0.2075 ; \mathrm{R}^{2}=0.9917\right)$ and expressed as mg gallic acid equivalents (GAE) per gram of sample in dry weight $(\mathrm{mg} / \mathrm{g})$ (Table 2). Where $\mathrm{y}$ is the 
absorbance at $760 \mathrm{~nm}$ and $\mathrm{x}$ is the total phenolic content in the extracts. Total phenolic content values were observed in methanolic extract of $D$. reflexa is $126 \pm 0.67 \mathrm{mgGE} / \mathrm{g}$.

\section{Total flavonoid content}

Polyphenolic compounds such as flavonoids are important adaptogenic compounds that help the body to adapt to the innumerable harsh environments. These defensive agents also improve human health from chronic ailments. The flavonoid content of the leaf methanolic extract of $D$. reflexa was determined by a colorimetric method using the Dowd technique and is found to be $54 \pm 0.67 \mathrm{mg}$ of gram equivalence of Quercetin at $415 \mathrm{~nm}$

(Table 2). The calibration curve was made by linear regression and the results were represented in triplicates. The total flavonoid content of the extract was calculated from the regression equation of the calibration curve $\left(\mathrm{Y}=7.6209 \mathrm{x}+0.083, \mathrm{R}^{2}=0.9957\right)$ and expressed as mg Quercetin equivalents per gram of sample in dry weight (mg $\mathrm{QE} / \mathrm{g})$.

\section{Total tannin content}

The total condensed tannin content was determined for the leaf methanolic extract of $D$. reflexa using the Broadhurst method and it is found that the extract is having $187.3 \pm 1.24 \mathrm{mg}$ of gram equivalence of Tannic acid at $500 \mathrm{~nm}$ (Table 2). A calibration curve $\left(\mathrm{Y}=7.0215 \mathrm{x}+0.0988, \mathrm{R}^{2}\right.$ $=0.9961)$ was plotted with various concentrations of tannic acid and mg tannic acid equivalents per gram of sample in dry weight (mg TAE/g).

\section{In vitro antioxidant assay}

$D P P H$ radical scavenging assay

In the present study, $D$. reflexa has exhibited significant free radical scavenging activity in a dose-dependent manner when compared to ascorbic acid. A standard curve $\left(\mathrm{Y}=6.808 \mathrm{x}+0.2284, \mathrm{R}^{2}=\right.$ 0.9947) was plotted using various concentrations of ascorbic acid and at a higher concentration (75 $\mu \mathrm{g} / \mathrm{mL})$, the extract displayed $71.37 \%$ of inhibition $\left(\mathrm{IC}_{50}\right.$ $=45.5)$ next to ascorbic acid $\left(79.27 \% ; \mathrm{IC}_{50}=\right.$ 39.82) and inferred to be a potent antioxidant (Table 3 and Figure 1). The ability of the extract to scavenge DPPH could also signify its ability to confront stress and subsequently the protective effects in the body.

\section{Nitric oxide radical scavenging activity}

When compared to the standard Ascorbic acid, D. reflexa leaf methanolic extract exhibited significant $\mathrm{NO}$ free radical scavenging activity in a dose-dependent manner (Table 3 and Figure 2). At higher concentration $(75 \mu \mathrm{g} / \mathrm{mL})$, the extract is showing $61.52 \%$ of inhibition with $\mathrm{IC}_{50}$ values $50.06 \mu \mathrm{g} / \mathrm{ml}$ followed by petroleum ether extract $71.34 \%$ with $\mathrm{IC}_{50}$ values 
$48.82 \mu \mathrm{g} / \mathrm{ml}$. Whereas for ascorbic acid it is found to be $80.13 \%$ with $\mathrm{IC}_{50}$ values $27.99 \mu \mathrm{g} / \mathrm{ml}$. The polyphenolic compounds such as tannins and flavonoids present in the $D$. reflexa may neutralize the free radicals liberated by the nitroprusside in the given procedure and may offer protection in the body linked to cellular stress.

\section{3-(4,5-dimethylthiazol-2-yl)-2,5-diphenyl tetrazolium bromide (MTT) assay}

From the results, it can be drawn that, after incubating with $D$. reflexa leaf methanolic extract, for $72 \mathrm{hr}$ at $37^{\circ} \mathrm{C}$ and $5 \% \mathrm{CO}_{2}$, it exhibited significant cytotoxicity against the selected cancer cell lines (Table 4). From the $\mathrm{IC}_{50}$ values, it is found that the prostate cancer (PC-3) cells are more sensitive $(9.84 \pm 1.12 \mu \mathrm{M})$ to the plant extract among others when compared to the standard Doxorubicin $\quad(1.74 \pm 1.31 \mu \mathrm{M})$ followed by Ovarian cancer (SKOV3; $14.02 \pm 2.23 \mu \mathrm{M}), \quad$ Breast cancer (MDAMB231; $14.85 \pm 1.16 \mu \mathrm{M}) \quad$ and Pancreatic cancer (Panc-1; 17.08 $\pm 1.34 \mu \mathrm{M})$.

Table 1: Phytochemical screening of leaf methanolic extract of $D$. reflexa

\begin{tabular}{cc}
\hline Phytochemicals & Present (+)/absent (-) \\
\hline Alkaloids & + \\
Glycosides & - \\
Saponins & + \\
Flavonoids & + \\
Steroids & - \\
Tannins & + \\
Proteins & - \\
Carbohydrates & + \\
Amino acids & + \\
\hline \multicolumn{2}{c}{+ present, - absent }
\end{tabular}

Table 2: Phytochemical profile of leaf methanolic extract of $D$. reflexa

\begin{tabular}{cc}
\hline Type & Values \\
\hline Total phenolic content & $126 \pm 0.67 \mathrm{mgGE} / \mathrm{g}$ \\
Total flavonoid content & $54 \pm 0.67 \mathrm{mgQE} / \mathrm{g}$ \\
Total tannin content & $187.3 \pm 1.24 \mathrm{mgTAE} / \mathrm{g}$
\end{tabular}

*All values are expressed as mean \pm SD for three determinations

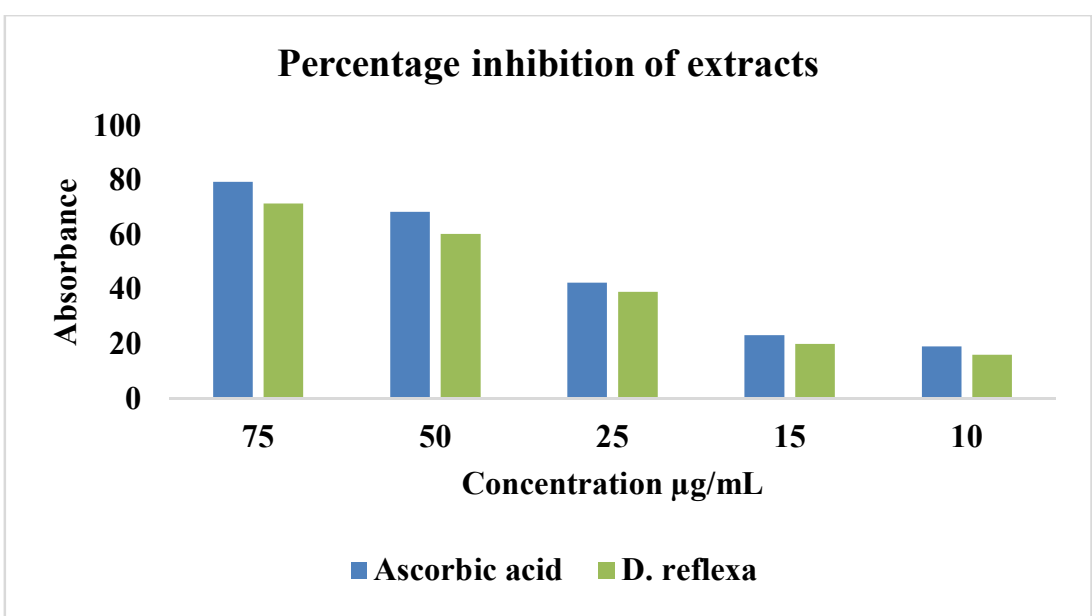

Figure 1: Percentage inhibition of extracts at different concentrations for DPPH assay 


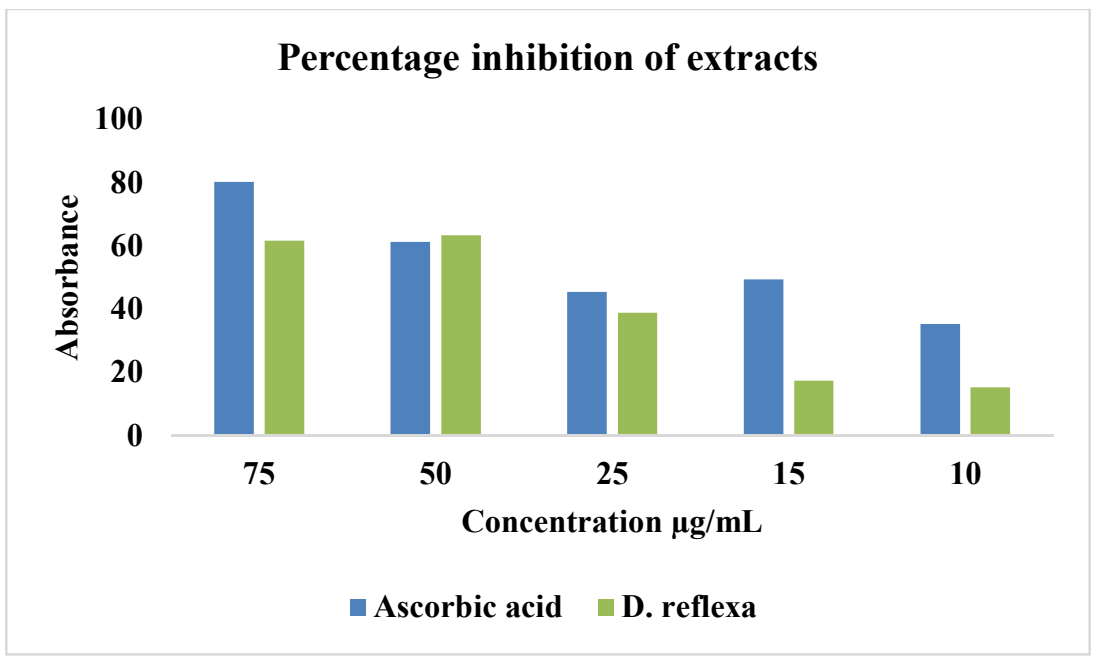

Figure 2: Percentage inhibition of extracts at different concentrations for NO free radical scavenging assay

Table 3: Percentage inhibition and $\mathrm{IC}_{50}$ values of extracts and ascorbic acid at different concentrations

\begin{tabular}{ccccc}
\hline \multirow{2}{*}{ Concentration $\mu \mathrm{g} / \mathrm{mL} \mathrm{L}$} & \multicolumn{2}{c}{ DPPH assay } & \multicolumn{2}{c}{ NO free radical assay } \\
\cline { 2 - 5 } & Ascorbic acid & D. reflexa & Ascorbic acid & D. reflexa \\
\hline 75 & 79.27 & 71.37 & 80.13 & 61.52 \\
50 & 68.38 & 60.27 & 61.18 & 63.28 \\
25 & 42.47 & 39.07 & 45.42 & 38.82 \\
15 & 23.3 & 20.17 & 49.36 & 17.39 \\
10 & 19.18 & 16.05 & 35.27 & 15.23 \\
$\mathrm{IC}_{\mathbf{5 0}} \mu \mathrm{g} / \mathrm{ml}$ & 39.82 & $45.5 \mu \mathrm{g} / \mathrm{mL}$ & $27.99 \mu \mathrm{g} / \mathrm{mL}$ & $48.82 \mu \mathrm{g} / \mathrm{mL}$ \\
\hline
\end{tabular}

Table 4: $\mathrm{IC}_{50}$ values of extract and Doxorubicin in MTT assay

\begin{tabular}{|c|c|c|}
\hline Treatment & D. reflexa & Doxorubicin \\
\hline SKOV3 & $\mathbf{1 4 . 0 2} \pm \mathbf{2 . 2 3}$ & $\mathbf{1 . 2 6} \pm \mathbf{1 . 2 5}$ \\
\hline MDAMB231 & $\mathbf{1 4 . 8 5} \pm \mathbf{1 . 1 6}$ & $\mathbf{2 . 7 3} \pm \mathbf{2 . 8 7}$ \\
\hline Panc-1 & $\mathbf{1 7 . 0 8} \pm \mathbf{1 . 3 4}$ & $\mathbf{2 . 1 5} \pm \mathbf{2 . 1 2}$ \\
\hline PC-3 & $\mathbf{9 . 8 4} \pm \mathbf{1 . 1 2}$ & $\mathbf{1 . 7 4} \pm \mathbf{1 . 3 1}$ \\
\hline B16F10 & $\mathbf{2 2 . 3 5} \pm \mathbf{1 . 3 4}$ & $\mathbf{2 . 8 1} \pm \mathbf{1 . 7 5}$ \\
\hline L132 & $\mathbf{6 6 . 6 5} \pm \mathbf{5 . 1 2}$ & $\mathbf{4 5 . 5 3} \pm \mathbf{2 . 2 5}$ \\
\hline
\end{tabular}

\section{DISCUSSIONS}

Secondary metabolites such as flavonoids and tannins are the principal polyphenolic composites formed as metabolic end products of the plant detoxification process. Concerning their ability to neutralize the excess free radicals through their structural features to react with them, they reinforce the protective mechanism. Plentiful documents are available to support the adaptogenic effect of polyphenolics in the management of various chronic and lifestyle disorders associated with stress. Natural antioxidants are preferred over synthetic agents considering their side effects in nutraceuticals for promoting health. ${ }^{18}$

Phytochemical screening of plant extracts either qualitative and quantitative methods will give a glance at their secondary metabolite profile and In vitro antioxidant activity screening of plant extract through 
DPPH assay and nitric oxide free radical assay is a primary step to evaluate their efficiency towards free radical stress and an important tool to understand their protective health benefits. ${ }^{19}$ Total phenolic, total flavonoid and total tannin content for methanol extracts of $D$. reflexa were estimated using standard protocols and In vitro antioxidant screening in DPPH and NO free radical assay was performed by comparing with the standard ascorbic acid.

The MTT assay was also performed using standard protocols using Cervical cancerHela, Ovarian cancer- SKOV3, Breast cancer-MDAMB231, Pancreatic cancerPanc-1, Prostate cancer-PC3, Murine melanoma -B16F10 and embryonic lung epithelial cell- L 132 by taking Doxorubicin a reference.

\section{CONCLUSION}

To wrap up the results, it can be perceived that $D$. reflexa is displayed potent cytotoxicity against pancreatic cancer, ovarian cancer and breast cancer cells, which can be correlated to the antioxidant activity observed in both methods. Since the extract is rich in phenolic compounds such as flavonoids and tannins, they may contribute directly or indirectly to the reported cytotoxicity. Further investigation is in progress to evaluate the complete phytochemical and pharmacological profile of the plant to justify its traditional applications and the reported antioxidant activity.

\section{ACKNOWLEDGEMENT}

The authors acknowledge the Department of Botany, Osmania University for providing necessary facilities.

\section{REFERENCES}

[1] SK. Dokuparthi, T. Rama Mohan Reddy. Antioxidant and nephroprotective activity of flavonoid rich fraction of Alphonsea sclerocarpa Thw". International journal of pharmaceutical sciences and drug research., 2021; 13(4),

[2] N. Chaves, A. Santiago, J. C. Alías. Quantification of the Antioxidant Activity of Plant Extracts: Analysis of Sensitivity and Hierarchization Based on the Method Used. Antioxidants (Basel, Switzerland)., 2020 Jan 15;9(1):76.

[3] Falzone L, Salomone S, Libra M Evolution of Cancer Pharmacological Treatments at the Turn of the Third Millennium. Front. Pharmacol. 2018; 9:1300.

[4] Kuruppu, Anchala I et al. Medicinal plants commonly used against cancer in traditional medicine formulae in Sri Lanka. Saudi pharmaceutical journal: SPJ: the official publication of the Saudi 
Pharmaceutical Society. 2019; 27(4): 565-573.

[5] Bray, Freddie et al. Global cancer statistics 2018: GLOBOCAN estimates of incidence and mortality worldwide for 36 cancers in 185 countries. CA: a cancer journal for clinicians., 2018; 68(6): 394-424.

[6] Mohammad Arif Ashraf. Phytochemicals as Potential Anticancer Drugs: Time to Ponder Nature's Bounty, BioMed Research International., 2020, 8602879, 1-7.

[7] Dhama, Kuldeep et al. Medicinal and Therapeutic Potential of Herbs and Plant Metabolites / Extracts Countering Viral Pathogens Current Knowledge and Future Prospects. Current drug metabolism. 2018; 19(3): 236-263.

[8] Sen, Tuhinadri, Samir Kumar Samanta. Medicinal plants, human health and biodiversity: a broad review. Advances in biochemical engineering/biotechnology. 2015; 147: 59-110.

[9] Randrianarivelojosia, M., Rasidimanana, V.T., Rabarison, H. et al. Plants traditionally prescribed to treat tazo (malaria) in the eastern region of Madagascar. Malar J., 2003; 2(25).
[10] Dokuparthi SK, Banerjee N, Kumar A, Singamaneni V, Giri AK and Mukhopadhyay S: Phytochemical investigation and evaluation of antimutagenic activity of the extract of Cuscuta reflexa Roxb by ames test. International Journal of Pharmaceutical Sciences and Research. 2014; 5(8): 3430-34

[11] Harborne JB. Phytochemical Methods. Chapman and hall Ltd., London: U.K., 1973: 49-188.

[12] Shukla A, Vats S, Shukla RK. Phytochemical Screening, Proximate Analysis and Antioxidant Activity of Dracaena reflexa Lam. Leaves. Indian Journal of Pharmaceutical Sciences. 2015;77(5):640-644.

[13] Aryal, Sushant et al. Total Phenolic Content, Flavonoid Content and Antioxidant Potential of Wild Vegetables from Western Nepal. Plants (Basel, Switzerland) 2019; 8(496).

[14] Broadhurst RB, jones WT. Analysis of condensed tannins using acidified vanillin. Journal of the Science of Food and Agriculture. 1978; 48(3):788-794

[15] Alam, Md Nur et al. Review on in vivo and in vitro methods 
evaluation of antioxidant activity." Saudi pharmaceutical journal: SPJ: the official publication of the Saudi Pharmaceutical Society vol. 2013; 21(2): 143-52.

[16] Marcocci, J.J. Marguire, M.T. Dro y-lefaiz, L. PackerThe nitric oxide scavenging properties of Ginkgo biloba extract Biochem. Biophys. Res. Commun., 1994; 201: 748755

[17] Ala, A A et al. Assessment of cytotoxicity of leaf extracts of Andrographis paniculata and Aspilia africana on murine cells in vitro. Archives of basic and applied medicine. 2018; 6(1): 6165.

[18] Arnous, A et al. Effect of principal polyphenolic components in relation to antioxidant characteristics of aged red wines. Journal of agricultural and food chemistry. 2001; 49(12): 5736-42.

[19] Savalekar, Kavita et al. Targeted phenolic profiling of Sauvignon blanc and Shiraz grapes grown in two regions of India by liquid chromatography-tandem mass spectrometry. Journal of food science and technology. 2019; 56(7): 3300-3312. 